\title{
Asthenopia in schoolchildren
}

This article was published in the following Dove Press journal:

Clinical Ophthalmology

28 August 2015

Number of times this article has been viewed

\author{
Manuel AP Vilela ${ }^{1,2}$ \\ Victor D Castagno ${ }^{2,3}$ \\ Rodrigo D Meucci ${ }^{3,4}$ \\ Anaclaudia G Fassa ${ }^{3,4}$ \\ 'Postdoctoral Program in \\ Epidemiology, ${ }^{2}$ Department of \\ Specialized Medicine - Ophthalmology, \\ ${ }^{3}$ Doctoral Program in Epidemiology, \\ ${ }^{4}$ Department of Social Medicine, \\ Federal University of Pelotas, Pelotas, \\ Rio Grande do Sul, Brazil
}

Correspondence: Manuel AP Vilela Postdoctoral Program in Epidemiology, Federal University of Pelotas, Avenida Duque de Caxias, 250, Fragata, 9600I 970 Pelotas, Rio Grande do Sul, Brazil Tel +55 5333092400

Email mapvilela@gmail.com
Objective: To assess asthenopia prevalence and associated factors in schoolchildren aged 6-16.

Methods: This was a cross-sectional study of all children attending the first to eighth grades at two public schools in the urban region of a medium-sized town in Southern Brazil between April and December 2012. A questionnaire on socioeconomic and cultural matters was answered by parents, while the children answered a questionnaire on asthenopia-related symptoms. The children underwent a complete visual function examination, including measurement of visual acuity, refraction test, cover test, stereopsis, heterophoria assessment, near point of convergence, and accommodative convergence/accommodation ratio.

Results: Asthenopia prevalence was $24.7 \%$ in a total sample of 964 children. Visual acuity of $20 / 25$ or better in both eyes was found in $92.8 \%$ of the children. The stereopsis test was normal in $99.4 \%$ of them, and some kind of strabismus was found in $3.5 \%$. About $37.8 \%$ had astigmatism, $71.6 \%$ had mild hyperopia, $13.6 \%$ had moderate hyperopia, and $6.1 \%$ were myopic. Near point of convergence was abnormal in $14.0 \%$ of the children, and the accommodative convergence/ accommodation ratio was found to be altered in $17.1 \%$ of them.

Conclusion: Children and adolescents have expressive prevalence of asthenopia. The prevalence of visual function alterations does not differ from the general population, and, therefore, they are not prerequisites. It is very important that its mechanisms and risk factors be better defined. Health professionals need to be on the lookout for complaints of visual fatigue because of its potential to influence learning and school performance.

Keywords: asthenopia, eyestrain, fatigue, visual, visual fatigue, eye fatigue

\section{Introduction}

Asthenopia can manifest itself through a variety of somatic or perceptive symptoms such as headache, watery, burning or itching eyes, blurred vision, eye ache, dry eye sensation, and double vision ${ }^{1-4}$ and frequently appears in association with activities requiring near viewing such as reading and writing whereby eye accommodative and vergence processes are more intense. ${ }^{5}$ Growing computer use (desktops, tablets, and laptops) and similar electronic equipment use (smartphones, e-book readers, video games) have increased the prevalence of asthenopia. ${ }^{6-12}$

The consequences of asthenopia in children and adolescents are not completely known, although there are indications that it may interfere with attention and academic performance. ${ }^{13-15}$ Particularly in adults, computer use-related asthenopia interferes significantly, but not permanently, with working capacity. ${ }^{16-19}$

There are few studies about asthenopia prevalence in elementary school students. In Australia, Ip et al studied 1,448 6-year-old children and found 12.6\% asthenopia prevalence. ${ }^{20}$ Asthenopia prevalence of $23.1 \%$ and $26.4 \%$ was found in two Swedish studies, respectively. ${ }^{5,21}$ With regard to associated factors, two studies detected significant association among decreased visual acuity, myopia, and accommodative 
dysfunctions, ${ }^{5,21}$ while another study did not find associated ophthalmological anomalies in $82 \%$ of children examined with asthenopia. ${ }^{20}$

In view of the scarcity of studies on this subject, the aim of this study is to assess asthenopia prevalence and associated factors in schoolchildren aged 6-16.

\section{Methods}

A cross-sectional study was conducted with all children attending the first to eighth grades at two public schools in the urban region of a medium-sized town in Southern Brazil between April and December 2012.

The study population was selected based on lists provided by the schools. As inconsistencies were found in the lists, homes were visited, and contact was made by telephone to identify children who were still on the lists but who were in fact studying at other schools. Children in this situation were excluded from the study.

Taking estimated asthenopia prevalence to be $20 \%, \pm 3$ percentage point accuracy, and a 95\% confidence interval (CI), a study population of 970 children was sufficient to study outcome prevalence. With regard to the analysis of associated factors, the study population was also sufficient to estimate risks of around 2.0 with minimum statistical power of $80 \%$ and a $95 \% \mathrm{CI}$, considering an exposed/unexposed ratio ranging from 13:1 (use of glasses) to 1:2 (internet at home).

Asthenopia was considered to be an outcome in situations in which a child reported having had tired and/or heavy eyes during the last week. Two questionnaires were administered by trained interviewers. One questionnaire related to socioeconomic and cultural issues was answered by parents or legal guardians. The other questionnaire related to the presence of asthenopia was answered by the children (Figure S1).

The children underwent a complete examination of visual functions, including the measurement of visual acuity, refraction test, cover test, stereopsis, heterophoria assessment, near point of convergence (NPC), and accommodative convergence/accommodation (AC/A) ratio.

Visual acuity and refractive status were assessed using the LogMAR chart at a distance of $4 \mathrm{~m}$ for each eye separately. Refraction was obtained using the fogging test with the aid of autorefraction and lensometry. Correction was maintained in the case of children having hyperopia equal to or greater than $1.25 \mathrm{D}$, myopia equal to or greater than $0.50 \mathrm{D}$, and astigmatism equal to or greater than $0.75 \mathrm{D}$. The cover test was performed on all children who achieved 20/25 visual acuity in both eyes after the refraction examination. For this study, children not achieving visual acuity of 20/25 in both eyes with the best possible correction did not undergo accommodative and binocular exams and were excluded. Children with anisometropia, but with visual acuity of 20/25 or better in both eyes with or without correction, remained in the study. Stereopsis was assessed using the Titmus test in all children who did not have tropias. Howell's near and far test with a $6 \mathrm{D}$ prism (lower base) was used in the right eye to measure horizontal heterophorias, and a $+1.00 \mathrm{D}$ flipper lens was used to measure the AC/A ratio (cutoff: $4: 1$ ). ${ }^{22}$ Thorington's test was used to measure vertical heterophorias. ${ }^{23}$ For the heterophorias, the cutoff point chosen were esophoria (far and close): 0 prismatic diopters (PD), exophoria (far) $2 \mathrm{PD}$, exophoria (close) $3 \mathrm{PD}$, and vertical heterophoria 0 PD. NPC was assessed using the Krimsky test and luminous focus with a transilluminator, where $6 \mathrm{~cm}$ was the cutoff (break) point chosen. ${ }^{24}$

Donders' push-up test was also performed during the study period. A third orthoptic technician thus measured accommodative amplitude using the same technique in an open space in $10 \%$ of the sample as a quality control measure.

Cycloplegia was performed using cyclopentolate $1 \%$ eye drops for a more accurate measurement of ametropias. A second drop was instilled 5 minutes after the first drop. Direct photomotor reflex and pupil size were observed after 20 minutes. In cases of photoreactive pupils or those with a diameter $\leq 6 \mathrm{~mm}$, a third drop was instilled in both eyes. After a further 15 minutes, signs of pupil dilation were checked again. Cycloplegic autorefraction was performed using a Potec auto refractor (model PRK-5000, Potec Co., Ltd., Daejeon, Korea) in both eyes. Auto refractor calibration was checked at the beginning of each working day using a $-5.25 \mathrm{D}$ eye model. Once children had been aligned with the device, eight measurements were taken of each eye. The eight measurements for each eye and their mean values were obtained through thermal printing.

The refractive examination and cycloplegic eye drop installation were performed by two trained orthoptic technicians supervised by an ophthalmologist.

The demographic variables studied were sex (male or female), age (in completed years), and skin color (White and non-White). Economic status was classified according to the criteria of the Brazilian Association of Survey Companies (Associação Brasileira de Empresas de Pesquisa). ${ }^{25}$ As this association's criterion for data on the level of schooling of the head of the family was not available in this study, it was 
replaced by the level of maternal schooling. With regard to environmental/behavioral variables, the time at which the child went to bed was dichotomized as regular (always at the same time, with 8 hours of sleep) and irregular, and the children were asked whether or not their families had a computer/internet and video games at home. Parents were also asked whether or not their children had video games or internet at home, but we did not estimate the time of use and whether or not they wore glasses.

Refractive status was categorized into (a) uncorrected emmetropic, hyperopic, or astigmatic at $<2 \mathrm{D}$; (b) uncorrected hyperopic and/or astigmatic at $\geq 2 \mathrm{D}$; (c) uncorrected myopic; and (d) those using glasses with any degree of ametropia. Four categories were created for spherical errors: (a) emmetropic, (b) mild hyperopia (+0.50-+1.99D), (c) moderate hyperopia $(\geq+2 \mathrm{D})$, and (d) myopic (greater than $-0.50 \mathrm{D})$. Astigmatism was divided into three categories: absent, mild $(+0.75-1.99 \mathrm{D})$, and moderate ( $\geq 2 \mathrm{D})$.

The proportions of the categories of each of the independent variables were then calculated. Outcome prevalence was calculated according to the independent variables using the chi-square heterogeneity test for differences between proportions. Poisson regression with robust variance and backward selection following a hierarchical model was used to analyze associated factors. ${ }^{26}$ Variables having $P<0.2$ were kept in the model to control confounders. The demographic and socioeconomic variables were included on the first level; environmental/behavioral variables and wearing glasses were included on the second level; and visual function estimates were included on the third level. Associations having $P<0.05$ were considered to be significant.

The study was approved by the Federal University of Pelotas Faculty of Medicine Research Ethics Committee and was authorized by the administration of both schools. The right of the study subjects and those legally responsible for them to refuse to take part and the right to confidentiality were ensured. Those who agreed to take part in the study undertook the visual function examinations and answered the questionnaires once their parents and/or legal guardians had signed the term of consent. Correction was prescribed for all cases requiring it, and those who needed ophthalmic care were treated at the Federal University of Pelotas Faculty of Medicine Ophthalmology Outpatients Department. The study complied with the requirements of the Declaration of Helsinki. ${ }^{27}$

\section{Results}

Some 1,022 of the total of 1,128 students attending both schools undertook the visual function examinations and answered the questionnaire about sight symptoms (9.4\% losses and refusals). Individuals aged 17 and over were also excluded. The final study population was 964 students.

About 37.5\% were aged 6-9, 55.6\% were aged 10-14, and $6.9 \%$ were aged $15-16$. About $55.2 \%$ of students were male. With regard to maternal schooling, $8.5 \%$ had attended school for $0-3$ years and $30.2 \%$ had completed their high school education. The majority of the children studied (58.1\%) belonged to economic class $\mathrm{C}$ (medium class), $78.8 \%$ were White, $92.8 \%$ did not use glasses, and $68.2 \%$ had never been seen by an ophthalmologist. The majority of the children had internet/computer (63.4\%) and video games $(77.0 \%)$ at home (Table 1$)$.

Asthenopia prevalence was $24.7 \%$ (95\% CI 22.2\%$27.5 \%$ ).

Visual acuity of 20/25 or better in both eyes was found in $92.8 \%$ of the children. The stereopsis test was normal in $99.4 \%$ of them, and some kind of tropia was found in $3.5 \%$. Vertical heterophoria was found in $1.2 \%$, and near and far horizontal heterophoria was found in $60.9 \%$ and $33.7 \%$, respectively. With regard to ametropias, only $8.7 \%$ of the children were emmetropic, $37.8 \%$ had some kind of astigmatism (31.8\% of these ranging from 0.75 to $2.0 \mathrm{D})$, $71.6 \%$ had mild hyperopia, $13.6 \%$ had moderate hyperopia, and $6.1 \%$ were myopic. NPC was $>6 \mathrm{~cm}$ in $14.0 \%$ of the children, and the $\mathrm{AC} / \mathrm{A}$ ratio was found to be altered in $17.1 \%$ of them (Table 1).

At the univariate analysis stage, age was directly associated with asthenopia and accounted for risks in 51\% of those aged 10-14 and in 69\% of those aged 15-16 compared with children in the age range of 6-9 years. No differences were found in relation to sex, economic status, or race. A $60 \%$ risk of asthenopia was associated with wearing glasses. Video games, computers, not going to bed on time, acuity below $20 / 25$, the presence of ametropias, near vertical heterophoria, near horizontal heterophoria, far horizontal heterophoria, $\mathrm{AC} / \mathrm{A}$ ratio, normal NPC, and stereopsis were not associated with asthenopia (Table 1).

With regard to the adjusted analysis, age was directly associated with asthenopia, and subjects aged 15-16 were 1.69 times more likely to have asthenopia than those aged 6-9 $(P=0.001)$. After adjusted analysis wearing glasses represented a $48 \%$ risk of asthenopia (Table 2 ).

Asthenopia was associated with other eye symptoms such as burning, aching, and itching, emphasizing wide-ranging variability and the possibility of overlapping asthenopia symptoms (1-4) (Table 1). 
Table I Sample description by demographic, economic and behavioural variables, ophthalmic examinations and self-reported symptoms. Asthenopia in schoolchildren in Pelotas according to the following independent variables: crude prevalence and association. Pelotas, Rio Grande do Sul, Brazil, 2012 ( $n=964)$

\begin{tabular}{|c|c|c|c|c|}
\hline Variable & $\mathbf{N}(\%)$ & $\begin{array}{l}\text { Prevalence \% } \\
(95 \% \mathrm{CI})\end{array}$ & $\begin{array}{l}\text { Prevalence ratio } \\
(95 \% \mathrm{Cl})\end{array}$ & $P$-value \\
\hline Age (years) & & & & $0.00 \mathrm{I}^{\mathrm{a}}$ \\
\hline $6-9$ & $361(37.5)$ & $18.6(\mid 4.5-22.6)$ & I & \\
\hline $10-14$ & $536(55.6)$ & $28.0(24.2-31.8)$ & $1.51(1.17-1.95)$ & \\
\hline $15-16$ & $67(6.9)$ & $31.3(19.9-42.7)$ & $1.69(1.11-2.56)$ & \\
\hline Sex & & & & $0.40^{\mathrm{b}}$ \\
\hline Male & $532(55.2)$ & $23.7(20.1-27.3)$ & I & \\
\hline Female & $432(44.8)$ & $25.9(21.8-30.1)$ & $1.09(0.88-1.37)$ & \\
\hline Maternal schooling (years) & & & & $0.4^{\mathrm{a}}$ \\
\hline $0-3$ & $81(8.5)$ & $29.6(19.5-39.8)$ & I & \\
\hline $4-7$ & $340(35.8)$ & $21.2(16.8-25.6)$ & $0.71(0.48-1.06)$ & \\
\hline $8-10$ & $242(25.5)$ & $24.8(19.3-30.3)$ & $0.84(0.56-1.25)$ & \\
\hline II or more & $287(30.2)$ & $27.5(22.3-32.7)$ & $0.93(0.63-1.36)$ & \\
\hline Economic status* & & & & $0.54^{\mathrm{a}}$ \\
\hline $\mathrm{AB}$ & $343(36.2)$ & $23.3(18.8-27.8)$ & I & \\
\hline $\mathrm{C}$ & $55 I(58.1)$ & $25.8(22.1-29.4)$ & $1.10(0.87-1.40)$ & \\
\hline DE & $54(5.7)$ & $24.1(12.3-35.9)$ & $1.03(0.62-1.72)$ & \\
\hline Race & & & & $0.69^{b}$ \\
\hline White & $760(78.8)$ & $25.0(21.9-28.1)$ & I & \\
\hline Non-white & $204(21.2)$ & $23.5(17.7-29.4)$ & $0.94(0.7|-| .24)$ & \\
\hline Wears glasses & & & & $0.004^{b}$ \\
\hline No & $891(92.8)$ & $23.5(20.7-26.2)$ & I & \\
\hline Yes & $69(7.2)$ & $37.7(26.0-49.4)$ & $1.61(1.16-2.22)$ & \\
\hline Prior ophthalmological examination & & & & $0.2^{\mathrm{b}}$ \\
\hline No & $657(68.2)$ & $23.3(20.0-26.5)$ & I & \\
\hline Yes & $306(31.8)$ & $27.4(22.1-32.5)$ & $1.18(0.94-1.48)$ & \\
\hline Internet/computer at home & & & & $0.40^{\mathrm{b}}$ \\
\hline No & $352(36.6)$ & $23.3(18.9-27.7)$ & I & \\
\hline Yes & $611(63.4)$ & $25.4(21.9-28.8)$ & $1.09(0.86-1.38)$ & \\
\hline Video game at home & & & & $0.62^{b}$ \\
\hline No & $221(23)$ & $25.8(20.0-31.6)$ & I & \\
\hline Yes & $742(77)$ & $24.3(21.2-27.4)$ & $0.94(0.73-1.22)$ & \\
\hline Acuity 0.8 or greater & & & & $0.58^{b}$ \\
\hline Absent & $69(7.2)$ & $21.7(11.8-31.7)$ & I & \\
\hline Present & $895(92.8)$ & $24.5(21.7-27.4)$ & $1.13(0.7 \mid-1.79)$ & \\
\hline Stereopsis & & & & $0.8 I^{b}$ \\
\hline Absent & $5(0.6)$ & $20.0(-36.0-75.5)$ & I & \\
\hline Normal & $824(99.4)$ & $24.4(21.5-27.3)$ & $\mathrm{I} .22(0.2 \mathrm{I}-7.08)$ & \\
\hline Strabismus & & & & $0.78^{\mathrm{b}}$ \\
\hline No & $858(96.5)$ & $24.6(21.7-27.5)$ & I & \\
\hline Yes & $31(3.5)$ & $22.6(7.0-38.2)$ & $0.92(0.47-1.78)$ & \\
\hline Vertical heterophoria & & & & $0.74^{b}$ \\
\hline No & $814(98.8)$ & $24.5(21.5-27.4)$ & I & \\
\hline Yes & $10(1.2)$ & $20.0(-10.0-50.1)$ & $0.82(0.24-2.84)$ & \\
\hline Near horizontal heterophoria & & & & $0.7^{\mathrm{b}}$ \\
\hline No & $320(39.1)$ & $23.8(19.1-28.4)$ & 1 & \\
\hline Yes & $499(60.9)$ & $25.0(21.2-28.9)$ & $1.05(0.82-1.35)$ & \\
\hline Far horizontal heterophoria & & & & $0.23^{b}$ \\
\hline No & $320(39.1)$ & $25.6(21.9-29.2)$ & I & \\
\hline Yes & 499 (60.9) & $22.4(17.4-27.3)$ & $0.88(0.67-1.14)$ & \\
\hline Spherical ametropia & & & & $0.90^{\mathrm{a}}$ \\
\hline Emmetropic & $84(8.7)$ & $31.0(20.9-41.0)$ & I & \\
\hline Mild hyperopia $(>+0.50 \mathrm{D}<+1.99 \mathrm{D})$ & $688(71.6)$ & $23.4(20.2-26.6)$ & $0.76(0.53-1.07)$ & \\
\hline Moderate hyperopia $(>+2.0 \mathrm{D})$ & $13 \mid(13.6)$ & $26.7(19.0-34.4)$ & $0.86(0.56-1.32)$ & \\
\hline Myopia $(>-0.50 \mathrm{D})$ & $58(6.1)$ & $25.9(14.2-37.5)$ & $0.84(0.49-1.43)$ & \\
\hline
\end{tabular}


Table I (Continued)

\begin{tabular}{|c|c|c|c|c|}
\hline Variable & $\mathbf{N}(\%)$ & $\begin{array}{l}\text { Prevalence \% } \\
(95 \% \mathrm{Cl})\end{array}$ & $\begin{array}{l}\text { Prevalence ratio } \\
(95 \% \mathrm{Cl})\end{array}$ & $P$-value \\
\hline Astigmatism & & & & $0.30^{\mathrm{a}}$ \\
\hline No & $598(62.2)$ & $23.6(20.2-27.0)$ & 1 & \\
\hline$>0.75 \mathrm{D}<2.0 \mathrm{D}$ & $306(31.8)$ & $26.5(21.5-31.4)$ & $1.12(0.89-1.42)$ & \\
\hline$>2.0 \mathrm{D}$ & $57(6)$ & $26.3(14.5-38.1)$ & I.I2(0.7I-I.76) & \\
\hline NPC & & & & $0.09^{b}$ \\
\hline$<6 \mathrm{~cm}$ & $479(50.1)$ & $26.9(22.9-30.9)$ & 1 & \\
\hline$\geq 6 \mathrm{~cm}$ & $478(49.9)$ & $22.1(18.4-25.9)$ & $0.82(0.65-1.02)$ & \\
\hline AC/A ratio $\#$ & & & & $0.57^{b}$ \\
\hline Abnormal & $163(17.1)$ & $26.4(19.5-33.2)$ & 1 & \\
\hline Normal & 788 (82.9) & $24.1(21.1-27.1)$ & $0.91(0.69-1.22)$ & \\
\hline Refractive status** & & & & $0.02^{\mathrm{a}}$ \\
\hline A & $678(74.3)$ & $22.9(19.7-26.0)$ & I & \\
\hline$B$ & $126(13.8)$ & $25.4(17.7-33.1)$ & I.II (0.80-I.54) & \\
\hline C & $39(4.3)$ & $20.5(7.3-33.8)$ & $0.90(0.48-1.69)$ & \\
\hline$D$ & $69(7.6)$ & $37.7(26.0-40.4)$ & $1.65(1.18-2.30)$ & \\
\hline Time to go to bed & & & & $0.50^{\mathrm{b}}$ \\
\hline Regular & $670(69.6)$ & $27.4(23.5-3 \mid .3)$ & I & \\
\hline Irregular & $293(30.4)$ & $21.5(17.8-25.3)$ & $0.92(0.72-1.18)$ & \\
\hline \multicolumn{5}{|l|}{ Asthenopia } \\
\hline No & $726(75.3)$ & & & \\
\hline Yes & $238(24.7)$ & & & \\
\hline Burning eyes & & & & $<0.001$ \\
\hline No & $726(75.3)$ & $12.9(10.5-15.4)$ & 1 & \\
\hline Yes & $238(24.7)$ & $60.5(54.2-66.8)$ & $4.67(3.77-5.79)$ & \\
\hline Eye ache & & & & $<0.00 I^{b}$ \\
\hline No & 705 (73.3) & $10.6(8.4-12.9)$ & 1 & \\
\hline Yes & $257(26.7)$ & $63.0(57.1-69.0)$ & $5.93(4.69-7.48)$ & \\
\hline Itching eyes & & & & $<0.00 \mathrm{I}^{\mathrm{b}}$ \\
\hline No & $583(60.5)$ & II.5 (8.9-14.I) & 1 & \\
\hline Yes & $380(39.5)$ & $44.7(39.7-49.8)$ & $3.89(3.03-5.01)$ & \\
\hline
\end{tabular}

Notes: aWald's linear trend test. 'Wald's heterogeneity test. *Economic status: (AB) high; (C) medium, (DE) low. **Refractive status: (A) mild hyperopia, mild simple astigmatism, does not wear glasses; (B) moderate hyperopia, moderate astigmatism, does not wear glasses; (C) myopia, does not wear glasses, (D) wears glasses. ${ }^{*}$ AC/A ratio: relationship between accommodation and convergence.

Abbreviations: $\mathrm{Cl}$, confidence interval; NPC, near point of convergence; $\mathrm{D}$, diopters.

\section{Discussion}

Asthenopia prevalence found in this study was similar to that found in a study conducted with 6- to 16-year-old schoolchildren in Sweden (23.1\%), ${ }^{5}$ but the questionnaires were not the same. In the Swedish study, the questions

Table 2 Asthenopia-associated factors following adjusted analysis. Pelotas, Rio Grande do Sul, Brazil, 2012 ( $n=964$ )

\begin{tabular}{|c|c|c|}
\hline Variable & PR (95\% Cl) & $P$-value \\
\hline \multicolumn{3}{|l|}{ First level } \\
\hline Age (years) & & $0.00 \mathrm{I}^{\mathrm{a}}$ \\
\hline 6-9 & 1 & \\
\hline $10-14$ & $1.55(1.19-2.01)$ & \\
\hline $15-16$ & $1.69(1.20-2.70)$ & \\
\hline \multicolumn{3}{|l|}{ Second level } \\
\hline Wears glasses & & $0.018^{b}$ \\
\hline No & I & \\
\hline Yes & $1.60(1.16-2.20)$ & \\
\hline NPC & & $0.08^{b}$ \\
\hline$<6 \mathrm{~cm}$ & I & \\
\hline$\geq 6 \mathrm{~cm}$ & $0.73(0.49-1.07)$ & \\
\hline
\end{tabular}

Notes: a'Wald's linear trend test. ' $W$ ald's heterogeneity test.

Abbreviations: $\mathrm{Cl}$, confidence interval; NPC, near point of convergence; $\mathrm{PR}$, prevalence ratio. used to define asthenopia were directed toward the group of symptoms relating to near visual effort. In Australia, $12.6 \%$ of the 6-year-old children had asthenopia-related complaints, but the difference in prevalence may be due to the difference in the age group assessed (not primed to interpret the symptoms) and to the fact that the questionnaire was answered by those legally responsible for the children. ${ }^{20}$ Another study performed in Sweden with children aged 6-10 found $34.7 \%$ asthenopia prevalence, although as a convenience sample was used prevalence may have been overestimated.

Ocular complaints - even tired and heavy eyes - in very young children are very inaccurate, but when present, or if associated with learning disabilities perceived by parents and teachers, eye examinations are very important. ${ }^{21}$ Since most studies showed no important relationship between asthenopia and visual acuity, screening only children with visual impairment would not detect a significant proportion of children with asthenopia. 
The combined frequency of asthenopia was $19.7 \%$ in a recent systematic review and meta-analysis of populationbased prevalence studies, and the relation between asthenopia and visual acuity, binocular dysfunctions, or refraction abnormalities was controversial. ${ }^{28}$

Increased asthenopia as age increases is in keeping with the literature. ${ }^{21}$ According to Scheiman and Wick, with effect from the fourth year of elementary education (at approximately 10 years old), children increase significantly the quantity and the difficulty of cognitive tasks and spend more time concentrating to learn. ${ }^{29}$ This increases the vergence and accommodative requirements directly related to asthenopia symptoms when reading and writing. Symptoms can therefore increase if children have an accommodative and/or binocular dysfunction, such as accommodative insufficiency. ${ }^{5}$ However, the lower prevalence found in younger children may be underestimated, in part, owing to the difficulty in their understanding the questions about asthenopia, as well as a possible bias created by those wishing to give the "right" answer to please the interviewer. ${ }^{13-15,30-32}$

The association between wearing glasses and the presence of asthenopia is in accordance with an Australian population-based study with 6-year-old children, in which those with asthenopia symptoms were seven times more likely to be using glasses compared with those who did not complain of having asthenopia-related symptoms, odds ratio $=7.195 \% \mathrm{CI}(4.6-10.9) .{ }^{20}$ This association may be due to reverse causality, given that asthenopia symptoms are frequently one of the criteria used by eye care professionals to prescribe glasses.

No association was found between asthenopia and sex, skin color, or economic status. Lack of association with sex was also found in the Australian population-based study with 6-year-old children $(P=0.39){ }^{20}$

The lack of association between an altered visual function examination and asthenopia reinforces the findings of the majority of studies. ${ }^{13-15,33,34}$ This aspect may be related in part to children not finishing activities that induce eye discomfort symptoms, that is, children who due to an undiagnosed visual function alteration feel discomfort when doing near activities requiring binocular, stereoscopic, and clear focus vision, naturally avoid reading, and, as a consequence, complain less about asthenopia. Moreover, many children do not report having asthenopia symptoms to their parents and teachers, principally because they are not aware of what it feels like to read comfortably. This can, in part, explain the lack of association related to NPC and AC/C ratio findings.
Two studies found association between accommodative inflexibility and accommodative insufficiency and asthenopia. ${ }^{5,21}$ Integrative analysis of these findings was not remembered in our study, it not being possible to classify the children in relation to specific accommodative and binocular dysfunctions. Two other studies indicated a direct relationship between asthenopia and myopia, astigmatism, ${ }^{5}$ and hyperopia greater than $3 \mathrm{D} .{ }^{20}$ Strabismus was also not associated with asthenopia, although in studies in which this association was significant, the possibility of part of the effect being due to high hyperopia (accommodative strabismus) must be remembered.

The association between asthenopia and the use of computers and other electronic devices has not been established among children. The use of video games or computers at home showed no association with asthenopia, although these activities were not quantified as to the amount of time spent doing them. This can underestimate the lack of association between eletronic devices and eyestrain. In both schools, children did not use computers in the classroom. . $3,3,6,18,35-39$

Analysis of the consistency of the data is hampered by the variability in the methods used by the different studies. Some studies use a small sample size. ${ }^{21}$ In the literature, the definition of a child with asthenopia varied a great deal between the studies.

A further difficulty with regard to comparing studies is the lack of a standardized questionnaire or an objective gold standard instrument for assessing asthenopia. In all population-based studies, asthenopia is self-reported by questionnaire and is subject to self-reporting bias having limited value due to the subjective nature of the outcome measure. ${ }^{28}$ Ip et $\mathrm{al}^{20}$ used the Sydney Myopia Study Questionnaire with more than 175 general questions and just 2 relating to complaints of eye ache or tiredness. ${ }^{40}$ The Visual Analogue Scale was used by Abdi on which students locate the intensity of their visual fatigue. ${ }^{5}$ Other questionnaires take into consideration characteristics associated with asthenopia but are used as an instrument for measuring symptom frequency before and after treatment for specific dysfunctions, such as the Convergence Insufficiency Symptom Survey ${ }^{41}$ and the College of Optometrists in Vision Development Quality of Life Outcomes Assessment. ${ }^{42,43}$ None of these instruments has been validated in Brazil. Because of this, we used similar questions to those adopted in the literature for parents and children with good correlation.

This study shows that schoolchildren have expressive visual fatigue prevalence, that the lack of association with refractive, binocular, or accommodative problems, and that 
the complaint increases with age. The limitations were related to the method of assessment of asthenopia (questionnaire) and the adopted cutoff break points that were derived from adult studies.

\section{Conclusion}

Children and adolescents have expressive prevalence of visual fatigue. Complaints increase in older children as the amount of learning activities, time spent concentrating, and cognitive maturity also increase. Those making use of optical correction are probably more aware of visual symptoms. Using computers or video games as a leisure activity was not found to be associated, but the time spent on these activities was not quantified. The prevalence of visual function alterations does not differ from the general population, and, therefore, they are not prerequisites for the onset of asthenopia. Considering that asthenopia is prevalent but little studied among children, it is important that its mechanisms and risk factors be better defined. In addition, health professionals need to be on the lookout for complaints of visual fatigue because of its potential to influence learning and school performance.

\section{Acknowledgment}

This article is funded by the Federal Agency for the Support and Evaluation of Graduate Education (CAPES) of the Brazilian Ministry of Education.

\section{Author contributions}

MAPV, VDC, and AGF made substantial contributions to conception and design, conducted the data analysis, and took part in drafting the article. MAPV and VDC revised the article. RDM conducted the data analysis and took part in revising the article. All authors read and approved the final manuscript.

\section{Disclosure}

The authors report no conflicts of interest in this work.

\section{References}

1. Nakazawa T, Okubo Y, Suwazono Y, et al. Association between duration of daily VDT user and subjective symptoms. Am J Ind Med. 2002;42(5):421-426.

2. Mvitu MM, Kaimbo WK. [Manifestations of asthenopia in Black subjects]. Bull Soc Belge Ophtalmol. 2003;(289):45-49. French.

3. Neugebauer A, Fricke J, Rüssmann W. Asthenopia: frequency and objective findings. Ger J Ophthalmol. 1992;1(2):122-124.

4. Graf HP, Flammer J. [Asthenopia in clinical practice: a comparative study of complaints, clinical findings and results of therapy in asthenopic patients]. Klin Monbl Augenheilkd. 1980;176(4):577-582. German.

5. Abdi S. Asthenopia in schoolchildren. [Thesis]. Stockholm: Karolinska Institutet. 2007:59.

6. Rosenfield M. Computer vision syndrome: a review of ocular causes and potential treatments. Ophthalmic Physiol Opt. 2011;31(5):502-515.
7. Agarwal S, Goel D, Sharma A. Evaluation of the factors which contribute to the ocular complaints in computer users. J Clin Diagn Res. 2013; 7(2):331-335.

8. Bergqvist UO, Knave BG. Eye discomfort and work with visual display terminals. Scand J Work Environ Health. 1994;20(1):27-33.

9. Carta A, Pasquini L, Lucchini R, et al. Studio delle relazioni fra astenopia ed alcuni parametri oftalmologici, neuropsicologie muscoloscheletrici in lavatori addetti al VDT [Study of the relationship of asthenopia and some ophthalmological, neuropsychological, and musculoskeletal parameters in workers assigned to VDT]. Med Lav. 2003;94(5):466-479. Italian.

10. Blehm C, Vishnu S, Khattak A, Mitra S, Yee RW. Computer vision syndrome: a review. Surv Ophthalmol. 2005;509(3):253-262.

11. Ong CN, Hoong BT, Phoon WO. Visual and muscular fatigue in operators using visual display terminals. J Hum Ergol. 1981;10:161-171.

12. Taino G, Ferrari M, Mestad IJ, et al. [Asthenopia and work at video display terminals: study of 191 workers exposed to the risk by administration of a standardized questionnaire and ophthalmologic evaluation]. G Ital Med Lav Ergon. 2006;28(10):487-497. Italian.

13. Dickinson CM, Rabbitt PMA. Simulated visual impairment: effects on text comprehension and reading speed. Clin Vision Sci. 1991; 4:301-308.

14. Conlon E, Lovegrove W, Hine T, Chekaluk E, Piatek K, HayesWilliams K. The effects of visual discomfort and pattern structure on visual search. Perception. 1998;27(1):21-33.

15. Conlon EG, Lovegrove WJ, Chekaluk E, Pattison PE. Measuring visual discomfort. Vis Cogn. 1999;6:637-666.

16. Kowalska M, Zejda JE, Bugajska J, et al. Eye symptoms in office employees working at computer stations. Med Pr. 2011;62(1):1-8.

17. Bhanderi DJ, Choudhary S, Doshi VG. A community-based study of asthenopia in computers operators. Ind J Ophthalmol. 2008;56(1): $51-55$

18. Mocci F, Serra A, Corrias GA. Psychological factors and visual fatigue in working with video display terminals. Occup Envirom Med. 2001;58(4):267-271.

19. Ye Z, Honda S, Abe Y, et al. Influence of work duration or physical symptoms on mental health among Japanese visual display terminal users. Ind Health. 2007;45(2):328-333.

20. Ip JM, Robaei D, Rochtchina E, et al. Prevalence of eye disorders in young children with eyestrain complaints. Am J Ophthalmol. 2006; 142(3):495-497.

21. Sterner B, Gellerstedt M, Sjöstrom A. Accommodation and the relationship to subjective symptoms with near work for young school children. Ophthalmic Physiol Opt. 2006;26(2):148-155.

22. Wong EP, Fricke TR, Dinardo C. Interexaminer repeatability of a new, modified prentice card compared with established phoria tests. Optom Vis Sci. 2002;79(6):370-375.

23. Lyon DW, Goss DA, Horner D, Downey JP, Rainey B. Normative data for modified Thorington phorias and prism bar vergences from the Benton-IU study. Optometry. 2005;76(10):593-599.

24. Hayes GJ, Cohen BE, Rouse MW, et al. Normative values for the nearpoint of convergence of elementary schoolchildren. Optom Vis Sci. 1998;75(7):506-512.

25. Associação Brasileira de Empresas de Pesquisa (ABEP). Critério de Classificação Econômica Brasil [Criteria for Brazilian Economic Classification]. São Paulo: ABEP; 2012. Portuguese.

26. Victora CG, Huttly SR, Fuchs SC, Olinto MTA. The role of conceptual frameworks in epidemiological analysis: a hierarchical approach. Int J Epidemiol. 1997;26(1):224-227.

27. World Medical Association [WMA]. World Medical Association Declaration of Helsinki. Tóquio: World Medical Association; 2004.

28. Vilela MAP, Pellanda LC, Fassa AG, Castagno VD. Prevalence of asthenopia in children: a systematic review with meta-analysis. J Pediatria. Epub 2015 May 16.

29. Scheinman M, Wick B. Clinical Management of Binocular Vision: Heterophoric, Accommodative, and Eye Movement Disorders. 3rd ed. Philadelphia: Lippincott, Williams \& Wilkins; 2008:748. 
30. Evans BJ, Patel R, Wilkins AJ, et al. A review of the management of 323 consecutive patients seen in a specific learning difficulties clinic. Ophthalmic Physiol Opt. 1999;19(6):454-466.

31. Grisham JD, Sheppard MM, Tran WU. Visual symptoms and reading performance. Optom Vis Sci. 1993;70:384-391.

32. Handler SM, Fierson WM, et al. Learning disabilities, dyslexia, and vision. Pediatrics. 2011;127(3):e818-e856.

33. Harle DE, Evans BJ. The optometric correlates of migraine. Ophthalmic Physiol Opt. 2004;24(5):369-383.

34. Conlon E, Hine T. The infuence of pattern interference on performance in migraine and visual discomfort groups. Cephalalgia. 2000;20(8): 708-713.

35. Gulmann NC, Hammerberg PE, Jensen LB, Sommerbeck KW, Orbaek K. Visual evoked potential in patients with cerebral asthenopia. Acta Neurol Scand. 1979;59(6):324-330.

36. Murata K, Araki S, Kawakami N, Saito Y, Hino E. Central nervous system effects and visual fatigue in VDT workers. Int Arch Occup Environ Health. 1991;63(2):109-113.

37. Sheeny JE, Hayes J, Engle J. Is all asthenopia the same? Optom Vis Sci. 2003;80:732-739.
38. Richter HO, Knez I. Superior short-wavelength central sensitivity in asthenopia during reflexive readjustments of ocular accommodation. Ophthalmic Physiol Optics. 2007;27(4):361-372.

39. Thiagarajan P, Ciuffreda KJ. Visual fatigue effects on vergence dynamics in asymptomatic individuals. Ophthalmic Physiol Opt. 2013; 33(6):642-651.

40. Center for Vision Research [database on the internet]. New South Wales: Center for Vision Research; 2014. Available from: http://www.cvr.org. $\mathrm{au} / \mathrm{sms}$. htm. Accessed 2014 October 23.

41. Borsting EJ, Rouse MW, Mitchell GL, et al. Validity and reliability of the revised convergence insufficiency symptom survey in children aged 9 to 18 years. Optom Vis Sci. 2003;80(2):832-838.

42. Maples WC. Test-retest reliability of the college of optometrists in vision development quality of life outcomes assessment. Optometry. 2000; 71(9):579-585.

43. Horwood AM, Toor S, Riddel PR. Screening for convergence insufficiency using the CISS is not indicated in young adults. Br J Ophthalmol. 2014; 98:679-683. 


\section{Supplementary material}

During the last week have you had sore eyes? (remind the child that we are not referring to the time of examination)

Any eye that hurts more?

Which eye hurts the most? (let the child point with their finger)

During the last week have you had burning (burning sensation) in the eye or around the eyes? (remind the child that we are not referring to the time of examination)

Any eye that burns more?

Which is the eye that burns more? (let the child point with their finger)

During the last week have you had itchy eyes? (remind the child that we are not referring to the time of examination)

Any eye that itches more?

Which is the eye that itches more? (let the child point with their finger)

During the last week have you had tired and heavy eyes? (remind the child that we are not referring to the time of examination)

Any eye that is more tired or heavy?

Which is the eye that is tired or weighs more? (let the child point with their finger)

During the last week have you had a headache?

Show me what part of the head that hurts the most (child points with their finger)

Figure SI Questionnaire about visual complaints in children (yes/no/sometimes).

\section{Publish your work in this journal}

Clinical Ophthalmology is an international, peer-reviewed journal covering all subspecialties within ophthalmology. Key topics include: Optometry; Visual science; Pharmacology and drug therapy in eye diseases; Basic Sciences; Primary and Secondary eye care; Patient Safety and Quality of Care Improvements. This journal is indexed on

Submit your manuscript here: http://www.dovepress.com/clinical-ophthalmology-journal
Dovepress

PubMed Central and CAS, and is the official journal of The Society of Clinical Ophthalmology (SCO). The manuscript management system is completely online and includes a very quick and fair peer-review system, which is all easy to use. Visit http://www.dovepress.com/ testimonials.php to read real quotes from published authors. 